\title{
A rare association: basal cell carcinoma in a vitiliginous macula
}

\author{
Jan Rustemeyer • Lutz Günther • Linda Deichert
}

Received: 24 June 2010 / Accepted: 28 June 2010 / Published online: 11 July 2010

(C) The Author(s) 2010. This article is published with open access at Springerlink.com

\begin{abstract}
Background Today, no proven significant association was detected between sun-exposed vitiliginous patches and nonmelanotic skin cancers. In fact, the occurrence of a basal cell carcinoma (BCC) in vitiliginous patches seems to be extremely rare.

Case report We present a case of a 33-year-old female patient suffering from $\mathrm{BCC}$ in a vitiliginous patch on the cheek. This is the first report of the occurrence of a sclerodermiform type of BCC in a vitiliginous macula.

Conclusion Our case report challenges the long-standing belief that the occurrence of $\mathrm{BCC}$ in vitiligo is nearly impossible. However, even if this association is apparently fortuitous, our report contributes to the awareness of the risk of $\mathrm{BCC}$ in young patients with vitiligo.
\end{abstract}

Keywords Vitiligo · Basal cell carcinoma - Non-melanotic skin cancer· Split-thickness skin graft

\section{Introduction}

The possible association of vitiligo and non-melanotic skin cancers (NMSC) has been discussed controversially and no

J. Rustemeyer $(\bowtie) \cdot$ L. Günther

Department of Oral and Maxillofacial Surgery,

Klinikum Bremen-Mitte,

School of Medicine of the University of Göttingen,

28177 Bremen, Germany

e-mail: janrustem@gmx.de

\section{Deichert}

Institute of Pathology, Klinikum Bremen-Mitte,

School of Medicine of the University of Göttingen,

28177 Bremen, Germany consensus had been achieved in the literature as to whether this association is significant or fortuitous. Few reports of occurrences of squamous cell carcinoma in patients with generalized vitiligo or after long-term psoralen ultraviolet-A therapy for vitiligo had been published previously [1-3]; basal cell carcinoma (BCC) in vitiliginous patches seems to be rare. Hence, reports could be found in recent literature only sporadically [4]. We present a case report of a young female suffering from BCC appearing on vitiligo macula in the cheek region and a review of the recent literature. To our knowledge, this is the first report of a sclerodermiform type of BCC associated with vitiligo. It is also important to note the young age of the patient.

\section{Case report}

A 33-year-old Caucasian female was referred from the department of dermatology to the oral and maxillofacial department at our clinic centre. When the patient first presented, a $5 \times 3.5-\mathrm{cm}$, erythematous, partly verrucous, partly plain and not well-circumscribed lesion located on a $6 \times 4.5$ depigmented vitiliginous patch on the left cheek was found (Fig. 1). This lesion had been present for 5 years and the patient had sought no treatment. No further depigmented patches on the body surface could be detected. The patient denied excessive sun exposure or sunburns in the past. A biopsy was performed and histological evaluation revealed a sclerodermiform BCC (Fig. 2). The total resection of the tumour included the resection of the whole vitiligo patch. Histological evaluation showed complete excision of the tumour with an infiltration depth of $7 \mathrm{~mm}$ and circumferential and basal security borders of $3 \mathrm{~mm}$. Following clarification about plastic reconstruction possibilities, the patient preferred a split-thickness skin graft 


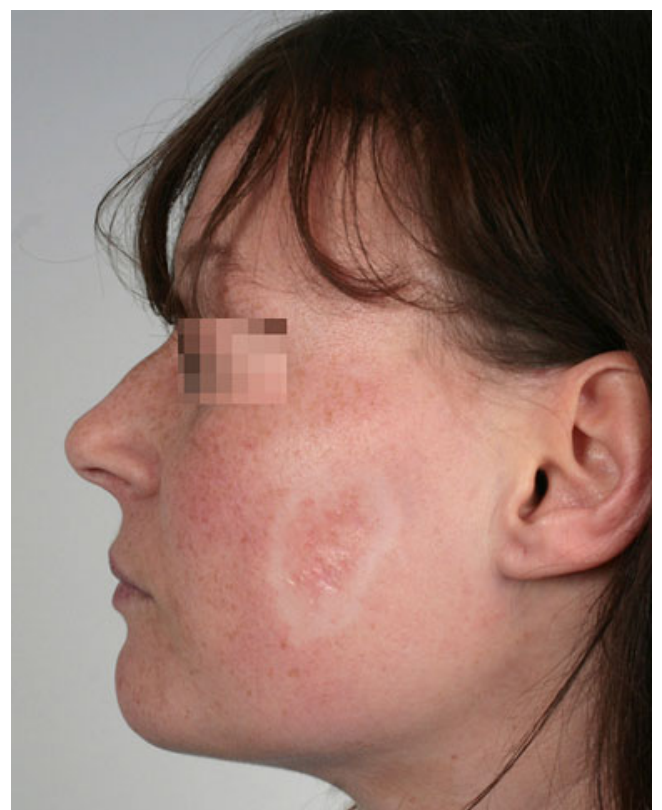

Fig. 1 Persistent non-healing $5 \times 3.5 \mathrm{~cm}$, erythematous, partly verrucous, partly plain irregular lesion located on a $6 \times 4.5$ vitiliginous macula on the left cheek of a young female

reconstruction with skin from a femoral donor site. After resection, the defect was temporarily covered with artificial skin substitute for 14 days until the tissue had nearly reached the level of the surrounding skin. In a second step, the defect was closed with a 4-mm split-thickness skin graft from the right femoral region. As expected, a difference in colour occurred towards the surrounding tissue after 5 weeks (Fig. 3). However, the patient was completely satisfied with the outcome.

\section{Discussion}

Ultraviolet radiation is a well-known risk factor in Caucasians for developing BCC with a latency period of

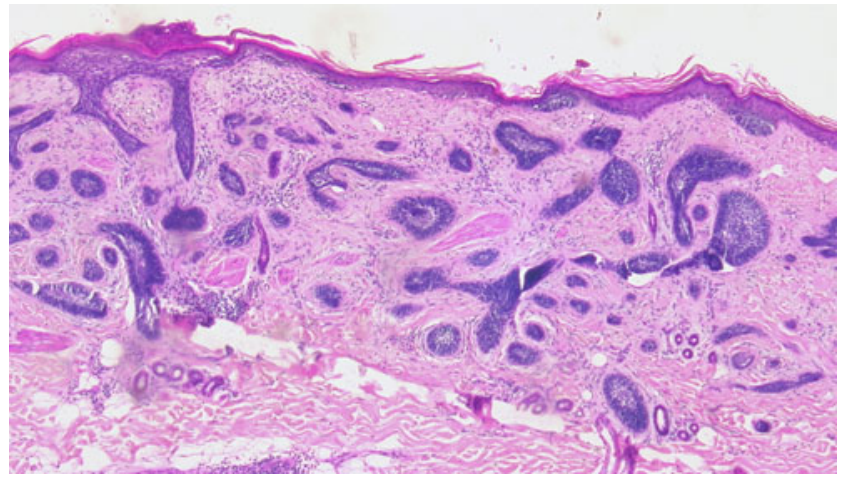

Fig. 2 Histological findings of a sclerodermiform type of basal cell carcinoma in a vitiliginous macula. Characteristic basaloid tumour cell clusters in the epidermis, typical peripheral palisading of nuclei, variable infiltrate of lymphocytes and plasma cells, and missing melanocytes (hematoxylin-eosin stain, $\times 10$ magnification)

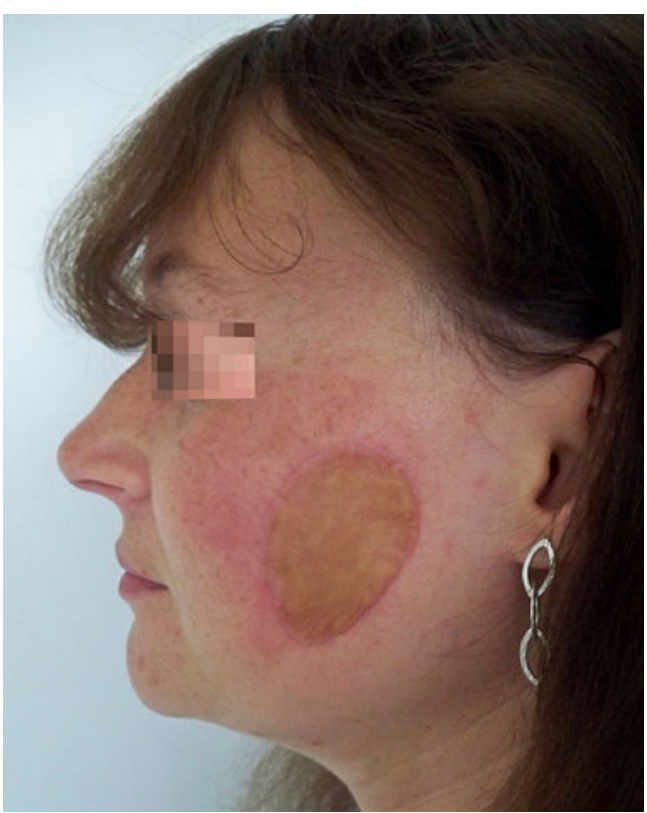

Fig. 3 Post- operative finding 5 weeks after reconstruction of the cheek with split-thickness skin graft. As expected, difference in colour occurred towards the surrounding tissue

decades. Considering that patients with vitiligo often have no protective pigment in sun-exposed vitiliginous skin areas, it would be expected that these patients have an increased risk for early photodamage and development of NMSC. Until now, however, there was no evidence found for sun-related damage in these patients histologically or by dermatoscopy. This was despite a significant number of cases with a history of sunburns in early childhood and continuous accumulation of millimolar epidermal peroxide [2]. Interestingly, this lack of sun-related damages could be linked to an overexpression of functional wildtype tumour suppressor gene p53 in vitiligo patches. This proposes that there is a protective function of this tumour suppressor gene in vitiligo, which could avoid lasting photodamage and the development of NMSC [5]. However, these findings are in contradiction to the occurrences of squamous cell carcinoma on a localized lesion of vitiligo, which has never been exposed to sunlight, e.g., on the genital mucous membrane [6], and the development of $\mathrm{BCC}$ in our case report.

Generally, in patients with vitiligo, it has to be determined whether the skin cancers were located on vitiliginous or normal-appearing skin. Hexel et al. [7] reported about six Caucasian patients with NMSC and vitiligo on sun-exposed sites. In only two patients NMSC occurred on the skin of the face. In only one of these patients BCC occurred on vitiliginous skin of the nasolabial fold and in the other patient in the normal preauricular skin. Both patients were male and older than 75 years. In this study, the incidence of NMSC among Caucasian patients 
with vitiligo was compared with cohorts from age-adjusted US populations. Results suggest that there may be an increased or equal risk of NMSC in patients with vitiligo. However, significant differences could not be obtained in comparison to patients without vitiligo. In our case report, the patient represented Fitzpatrick skin phototype II [8] and was therefore more susceptible to skin cancer. Although the patient was young, the localization in a vitiliginous patch and the low sun exposure are in contrast to the usual risk factors for BCC. Obviously, other factors, such as spontaneous mutations on the genetic level [9], might play a more important role. Further studies with large cohorts providing histological as well as immunohistochemical findings are warranted to enlighten the relationship between vitiligo and NMSC. Our case report contributes to the awareness of the risk of developing $\mathrm{BCC}$ even in young patients with vitiligo.

Conflicts of interest The authors declare that they have no conflicts of interest.

Open Access This article is distributed under the terms of the Creative Commons Attribution Noncommercial License which permits any noncommercial use, distribution, and reproduction in any medium, provided the original author(s) and source are credited.

\section{References}

1. Seo S1, Kim IH (2001) Squamous cell carcinoma in a patient with generalized vitiligo. J Am Acad Dermatol 45:227-229

2. Schallreuter KU, Tobin DJ, Panske A (2002) Decreased photodamage and low incidence of non-melanoma skin cancer in 136 sun-exposed Caucasian patients with vitiligo. Dermatology 204:194-201

3. Park HS, Lee YS, Chun DK (2003) Squamous cell carcinoma in vitiligo lesion after long-term PUVA therapy. J Eur Acad Dermatol Venereol 17:578-580

4. Arnon O, Mamelak AJ, Goldberg LH (2008) Basal cell carcinoma arising in a patient with vitiligo. J Drugs Dermatol 7:1075-1076

5. Schallreuter KU, Behrens-Williams S, Khalip TP, Picksley SM, Peters EM, Marles LK, Westerhof W, Miehe B, Fanghänel J (2003) Increased epidermal functioning wild-type p53 expression in vitiligo. Exp Dermatol 12:268-277

6. Ravi S, Ramesh V, Misra RS (1990) Squamous cell carcinoma on a patch of mucosal vitiligo. Indian J Dermatol Venereol Leprol $56: 64-65$

7. Hexsel CL, Eide MJ, Johnson CC, Krajenta R, Jacobsen G, Hamzavi I, Lim HW (2009) Incidence of nonmelanoma skin cancer in a cohort of patients with vitiligo. J Am Acad Dermatol 60:929933

8. Roberts WE (2009) Skin type classification system old and new. Dermatol Clin 27:529-533

9. Prior SL, Griffiths AP, Lewis PD (2009) A study of mitochondrial DNA D-loop mutations and p53 status in nonmelanoma skin cancer. Br J Dermatol 161:1067-1071 